\title{
Equations of Motion for the Vertical Rigid-Body Rotor: Linear and Nonlinear Cases
}

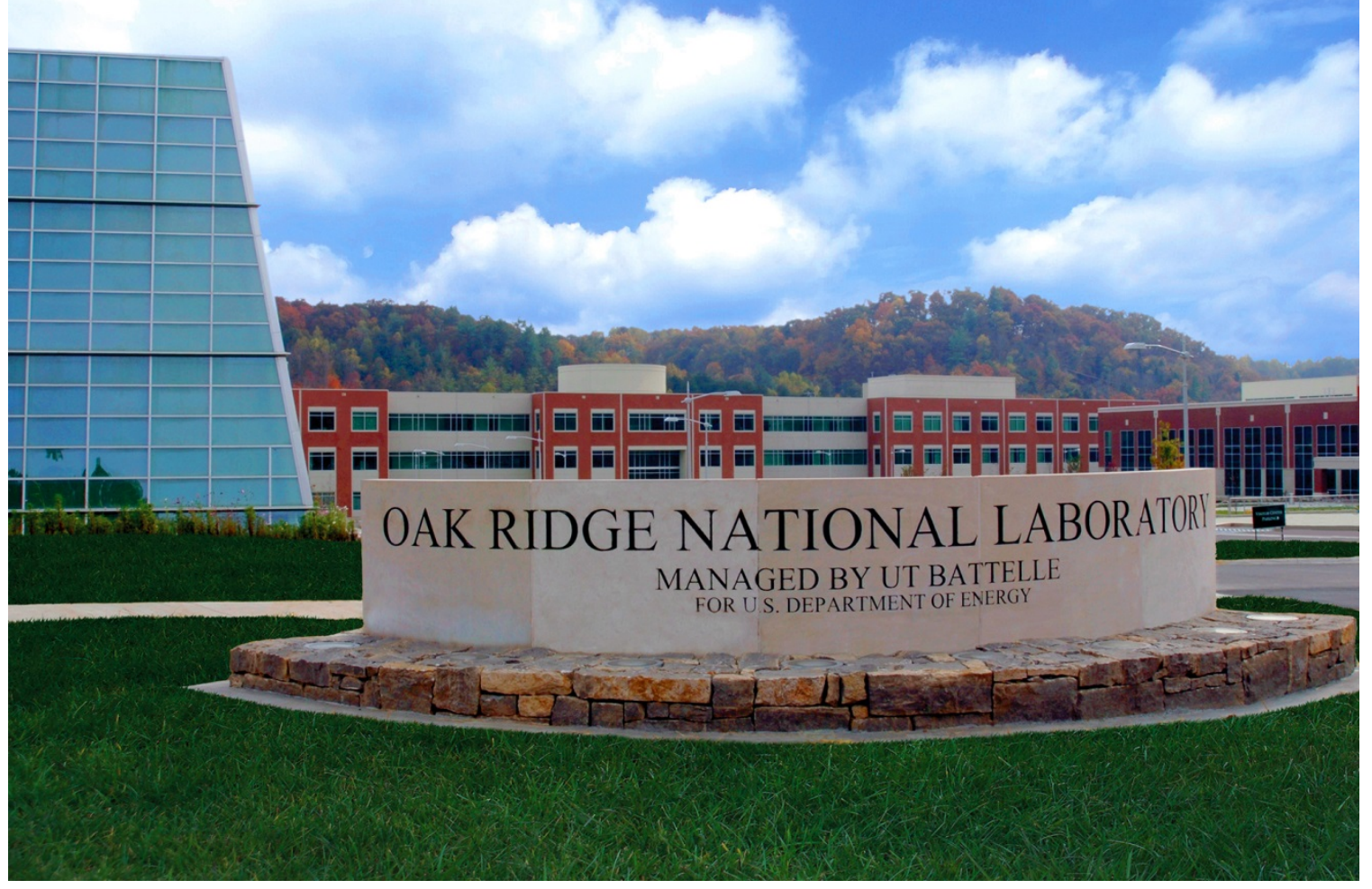

Hector Laos

December 2021 


\title{
DOCUMENT AVAILABILITY
}

Reports produced after January 1, 1996, are generally available free via US Department of Energy (DOE) SciTech Connect.

Website www.osti.gov

Reports produced before January 1, 1996, may be purchased by members of the public from the following source:

\author{
National Technical Information Service \\ 5285 Port Royal Road \\ Springfield, VA 22161 \\ Telephone 703-605-6000 (1-800-553-6847) \\ TDD 703-487-4639 \\ Fax 703-605-6900 \\ E-mail info@ntis.gov \\ Website http://classic.ntis.gov/
}

Reports are available to DOE employees, DOE contractors, Energy Technology Data Exchange representatives, and International Nuclear Information System representatives from the following source:

Office of Scientific and Technical Information

PO Box 62

Oak Ridge, TN 37831

Telephone 865-576-8401

Fax 865-576-5728

E-mail reports@osti.gov

Website http://www.osti.gov/

This report was prepared as an account of work sponsored by an agency of the United States Government. Neither the United States Government nor any agency thereof, nor any of their employees, makes any warranty, express or implied, or assumes any legal liability or responsibility for the accuracy, completeness, or usefulness of any information, apparatus, product, or process disclosed, or represents that its use would not infringe privately owned rights. Reference herein to any specific commercial product, process, or service by trade name, trademark, manufacturer, or otherwise, does not necessarily constitute or imply its endorsement, recommendation, or favoring by the United States Government or any agency thereof. The views and opinions of authors expressed herein do not necessarily state or reflect those of the United States Government or any agency thereof. 
Enrichment Science and Engineering Division

\title{
EQUATIONS OF MOTION FOR THE VERTICAL RIGID-BODY ROTOR: LINEAR AND NONLINEAR CASES
}

\author{
Hector Laos
}

December 2021

Prepared by OAK RIDGE NATIONAL LABORATORY

Oak Ridge, TN 37831-6283

managed by

UT-BATTELLE, LLC

for the

US DEPARTMENT OF ENERGY

under contract DE-AC05-00OR22725 



\section{CONTENTS}

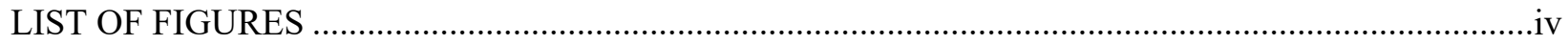

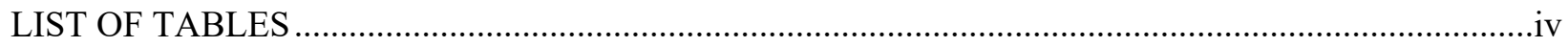

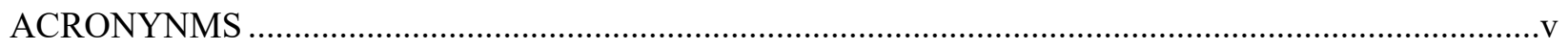

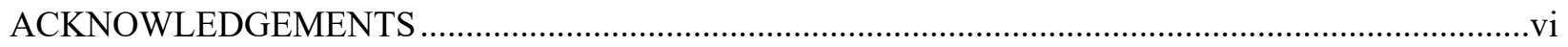

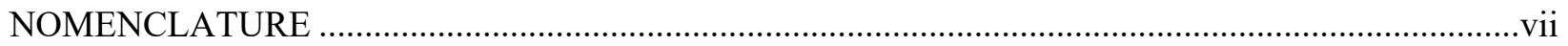

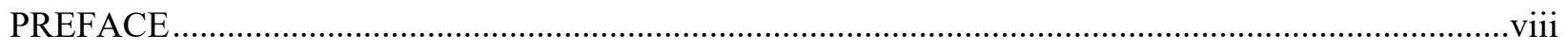

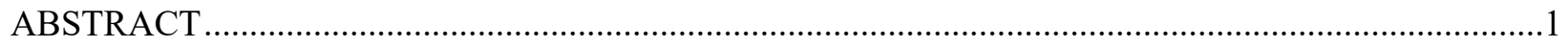

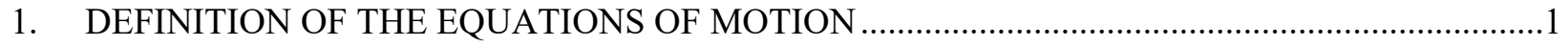

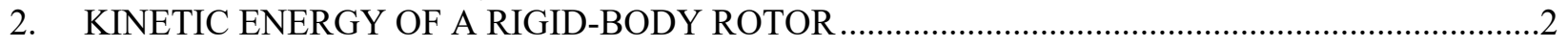

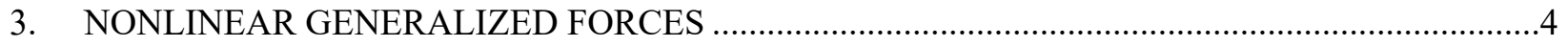

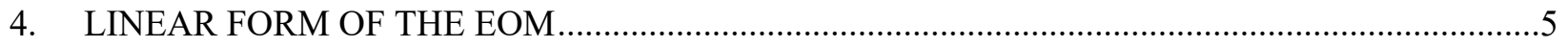

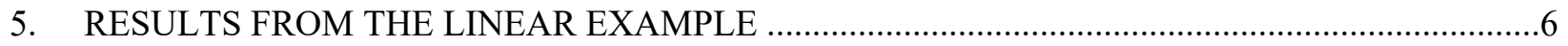

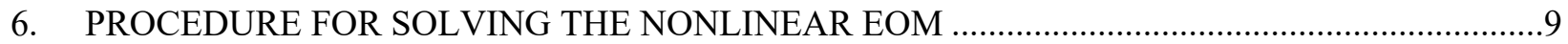

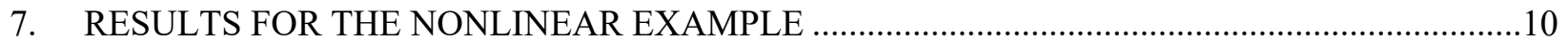

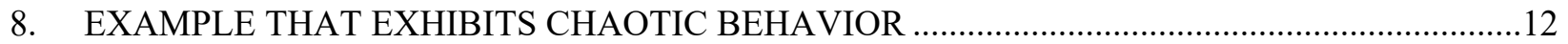

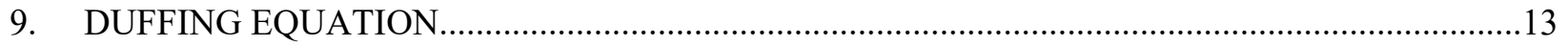

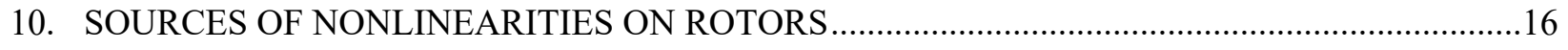

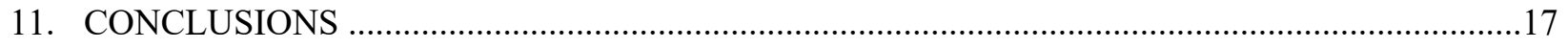

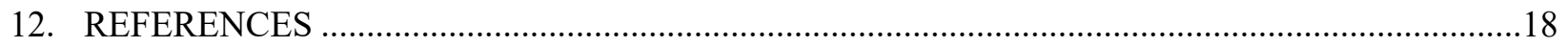

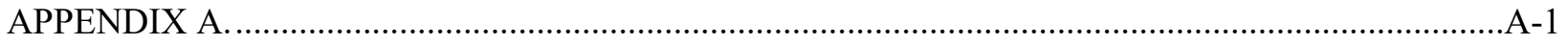




\section{LIST OF FIGURES}

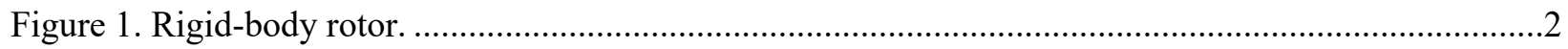

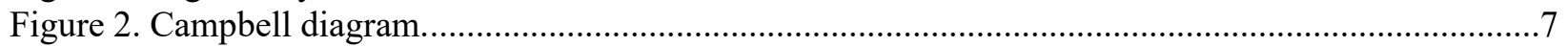

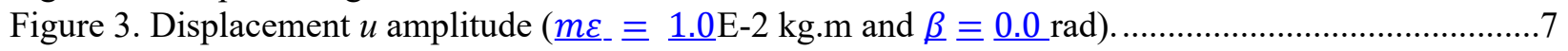

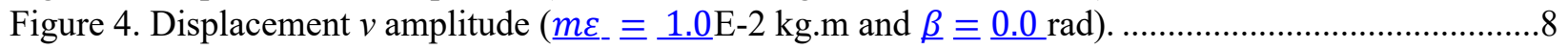

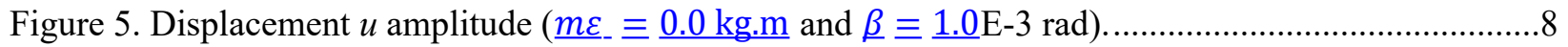

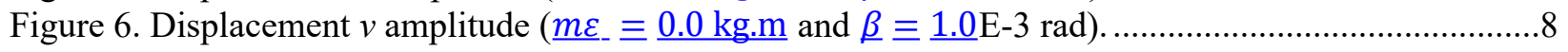

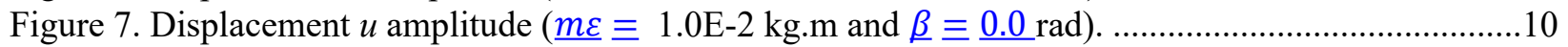

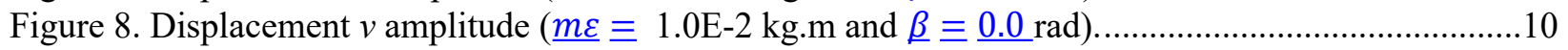

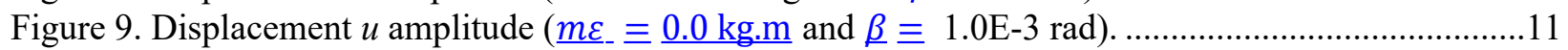

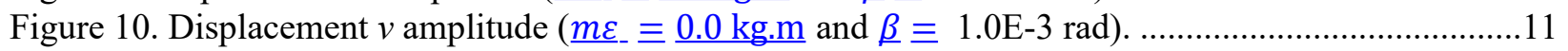

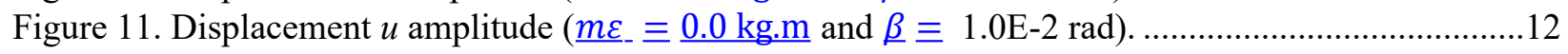

Figure 12. Displacement $v$ amplitude $(\underline{m \varepsilon}$. $\equiv \underline{0.0 \mathrm{~kg} . \mathrm{m}}$ and $\underline{\beta} \equiv 1.0 \mathrm{E}-2 \mathrm{rad})$....................................12

Figure 13. Orbits on the $x-y$ plane shown in time (vertical axis). ........................................................13

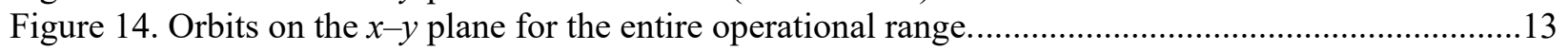

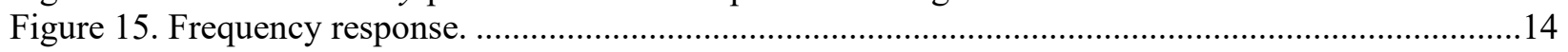

Figure 16. Frequency response ( $\underline{\mu} \equiv \underline{0.0400)}$; jump phenomena - paths to follow..............................15

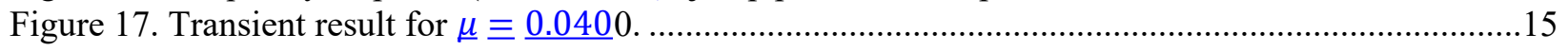

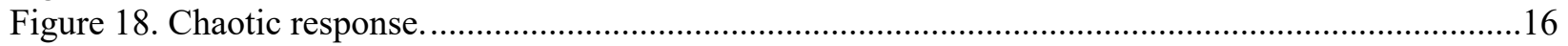

\section{LIST OF TABLES}

Table 1. Displacement and velocities at the supports. .........................................................................

Table 2. Data from the Dynamics of Rotating Machines [9] .............................................................6 


\section{ACRONYMS}

CG center of gravity

EOM equations of motion 


\section{ACKNOWLEDGMENTS}

The author wishes to recognize Brian Damiano, $\mathrm{PhD}$, for his full support with this initiative. 


\section{NOMENCLATURE}

\section{Greek Variables:}

$\begin{array}{ll}\theta & \text { Angular displacement }(\mathrm{rad}) \\ \psi & \text { Angular displacement }(\mathrm{rad}) \\ \phi & \text { Angular rotation (rad) } \\ \Omega & \text { Angular speed at steady-state conditions }(\mathrm{rad} / \mathrm{s}) \\ \alpha & \text { Angular acceleration }\left(\mathrm{rad} / \mathrm{s}^{2}\right) \\ \omega_{x}, \omega_{y}, \omega_{z} & \text { Angular velocities on } \boldsymbol{x}, \boldsymbol{y}, \boldsymbol{z} \\ \beta & \text { Rotational unbalance }(\mathrm{rad}) \\ \gamma & \text { Phase angle (in } \beta)(\mathrm{rad}) \\ m \varepsilon & \text { Lateral unbalance }(\mathrm{kg} \cdot \mathrm{m}) \\ \delta & \text { Phase angle (in } m \varepsilon) \\ \mu & \text { Nonlinear stiffness coefficient }\left(\mathrm{N} / \mathrm{m}^{3}\right) \\ \omega_{n} & \text { Natural frequency }(\mathrm{rad} / \mathrm{s})\end{array}$

\section{More Variables \& Definitions:}

\section{$\mathcal{L} \quad$ Lagrangian}

$q_{i}, q_{i}, \mathscr{q}_{i} \quad$ General coordinate and its derivatives; applicable to all time (t) parameters

$F_{q_{i}}$

$T_{D}$

General force coordinate applied on $q_{i}$

$a, b \quad$ Elevations from center of gravity (m)

$I_{d} \quad$ Diametral moment of inertia $\left(\mathrm{kg} \cdot \mathrm{m}^{2}\right)$

$I_{p} \quad$ Polar moment of inertia $\left(\mathrm{kg} \cdot \mathrm{m}^{2}\right)$

$m_{d} \quad$ Rigid-body mass $(\mathrm{kg})$

$g \quad$ Acceleration of gravity $\left(\mathrm{m} / \mathrm{s}^{2}\right)$

$\boldsymbol{x}, \boldsymbol{y}, \boldsymbol{z} \quad$ Coordinates of reference

$u \quad$ Displacement on axis $\boldsymbol{x}(\mathrm{m})$

$v \quad$ Displacement on axis $\boldsymbol{y}(\mathrm{m})$

$k_{x 1}, k_{x 2} \quad$ Stiffness at locations 1 and 2 on axis $\boldsymbol{x}(\mathrm{N} / \mathrm{m})$

$k_{y 1}, k_{y 2} \quad$ Stiffness at locations 1 and 2 on axis $\boldsymbol{y}(\mathrm{N} / \mathrm{m})$

$c_{x 1}, c_{x 2} \quad$ Damping at locations 1 and 2 on axis $\boldsymbol{x}(\mathrm{N} . \mathrm{s} / \mathrm{m})$

$c_{y 1}, c_{y 2} \quad$ Damping at locations 1 and 2 on axis $\boldsymbol{y}(\mathrm{N} . \mathrm{s} / \mathrm{m})$

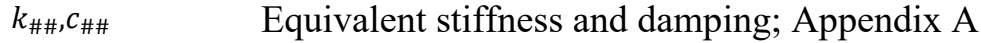

$c$

$F$

Damping (N.s/m)

Excitation force $(\mathrm{N})$

A Amplitude of the nonlinear example (m)

\section{Vectors and Matrices:}

[M] Mass matrix

[G] Gyroscopic matrix

$[C] \quad$ Damping matrix

$[K] \quad$ Stiffness matrix

$\{0\} \quad$ Zero vector

$\{U\} \quad$ Unbalance vector 


\section{PREFACE}

This paper started as a presentation to the members of Oak Ridge National Laboratory's Machine Dynamics Group, and it has had several iterations. The paper was later presented at the IMAC 39 Conference under the same title [1], and this version includes a new section to explain the nonlinear phenomena with the Duffing equation. The present document includes an entire section on sources of nonlinearities on rotors (not included in previous versions) that shows several mechanisms that produce instabilities on the rotor-bearing systems. 


\begin{abstract}
Centuries ago, the prolific mathematician Leonhard Euler (1707-1783) wrote down the equations of motion (EOM) for the heavy symmetrical top with one point fixed. The resulting set of equations turned out to be nonlinear and had a limited number of closed-form solutions.

Today, tools such as transfer matrix and finite elements enable the calculation of the rotordynamic properties for rotor-bearing systems. Some of these tools rely on the "linearized" version of the EOM to calculate the eigenvalues, unbalance response, or transients in these systems.

In fact, industry standards mandate that rotors be precisely balanced to have safe operational characteristics. However, in some cases, the nonlinear aspect of the EOM should be considered.

The purpose of this paper is to show examples of how the linear vs. nonlinear formulations differ. This paper will also show how excessive unbalance is capable of dramatically altering the behavior of the system and can produce chaotic motions associated with the "jump" phenomenon.
\end{abstract}

\title{
1. DEFINITION OF THE EQUATIONS OF MOTION
}

The EOMs are defined using the Lagrange equations [2]:

$$
\frac{d}{d t}\left(\frac{\partial \mathcal{L}}{\partial q_{i}}\right)-\frac{\partial \mathcal{L}}{\partial q_{i}}=F_{q_{i}}
$$

where the Lagrangian $\mathcal{L}\left(\mathcal{L}=T_{D}-U_{D}\right)$ is defined as the difference between the kinetic energy $\left(T_{D}\right)$ and the potential energy $\left(U_{D}\right)$. Also, $i(1 \leq i \leq N)$ is the number of degrees of freedom, the generalized independent coordinates are $q_{i}$, and the generalized forces are $F_{q_{i}}$.

The generalized coordinates in the vertical rigid rotor are $u, v, \theta, \psi$, as shown in Figure 1 . The Newtonian approach (not the Lagrangian) will be used for the external forces, including springs and dampers $\left(F_{q_{i}}=-F_{u},-F_{v},-F_{\theta},-F_{\psi}\right)$, and for the effect of the rotor weight. This will cancel out the potential energy $\left(U_{D}\right)$ in the Lagrangian, and the expression in Eq. (1) is reduced to the following [3]:

$$
\frac{d}{d t}\left(\frac{\partial T_{D}}{\partial}\right)-\frac{\partial T_{D}}{\partial q_{i}}=F_{q_{i}}
$$

For the sake of clarity, the definition of the terms in Eq. (2), $T_{D}$ and $F_{q_{i}}$, will be explained in different sections. 


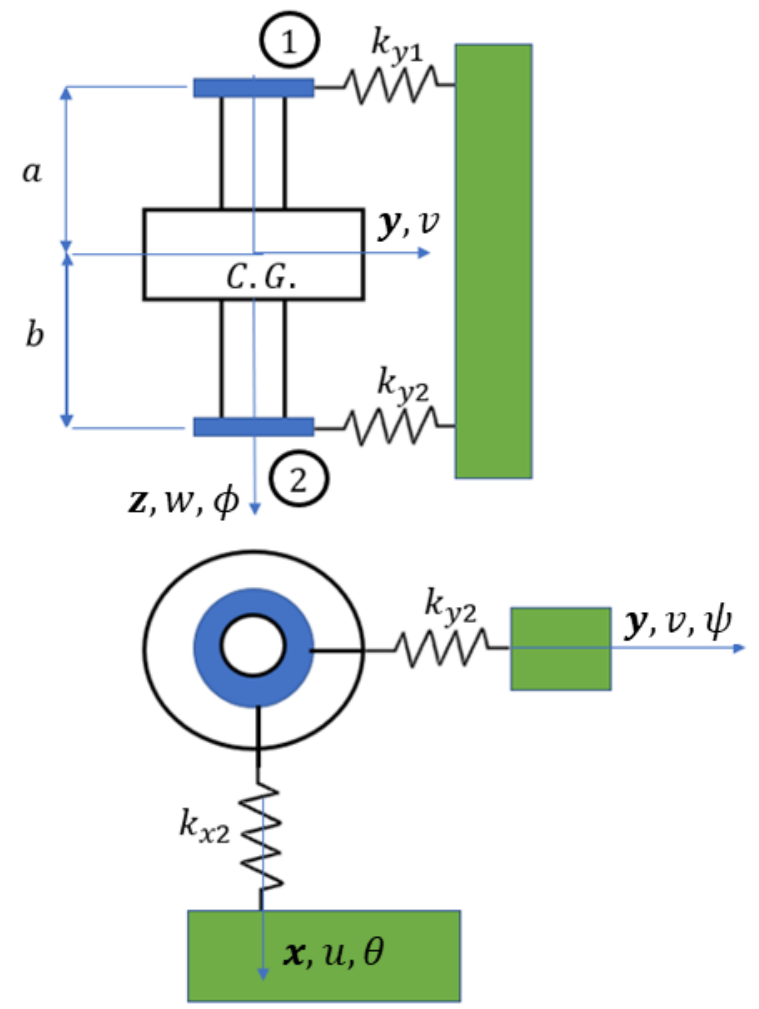

Figure 1. Rigid-body rotor.

\section{KINETIC ENERGY OF A RIGID-BODY ROTOR}

The kinetic energy of a rigid-body rotor is as follows [4]:

$$
T_{D}=\frac{1}{2} m_{d}\left(\dot{u}^{2}+\dot{v}^{2}+\dot{w}^{2}\right)+\frac{1}{2} I_{d}\left(\omega_{x}^{2}+\omega_{y}^{2}\right)+\frac{1}{2} I_{p} \omega_{z}^{2} .
$$

Figure 1 shows the vertical rigid-body rotor with its system of coordinates, the location of the center of gravity (CG), and the parameters that will be used to define the displacements and rotations at the CG.

In this report, only the lateral displacements $(u, v)$ and the rotations $(\theta, \psi, \phi)$ were considered. All lateral displacement and rotations coincide with the $\mathrm{CG}$.

The axial movement $w$ is assumed to be decoupled from the lateral displacements. Therefore, $\dot{w}$ will not be considered any further in this paper.

The rotor spin angle $\phi$ will be kept because the transient unbalance is a function of $\phi$ and its derivatives.

The angular velocity vector $\{\omega\}$ will be defined as a function of the angular velocities of the Euler angles: $\dot{\theta}, \dot{\psi}, \dot{\phi}$.

$$
\{\omega\}^{T}=\left\{\begin{array}{lll}
\omega_{x} & \omega_{y} & \omega_{z}
\end{array}\right\}
$$


The process consists of a series of rotations starting from an initial axis $\{Y\}$, as shown in the following sequence [5], [6], [7]:

$$
\{\omega\}=\dot{\psi}\{Y\}+\dot{\theta}\left\{x_{1}\right\}+\dot{\phi}
$$

and

$$
\left\{\begin{array}{l}
\omega_{x} \\
\omega_{y}
\end{array}\right\}=\left\{\begin{array}{l}
0 \\
0 \\
\dot{\phi}
\end{array}\right\}+\left[\begin{array}{ccc}
\cos \phi & \sin \phi & 0 \\
-\sin \phi & \cos \phi & 0 \\
0 & 0 & 1
\end{array}\right]\left\{\begin{array}{l}
\dot{\theta} \\
0 \\
0
\end{array}\right\}+\left[\begin{array}{ccc}
\cos \phi & \sin \phi & 0 \\
-\sin \phi & \cos \phi & 0 \\
0 & 0 & 1
\end{array}\right]\left[\begin{array}{ccc}
1 & 0 & 0 \\
0 & \cos \theta & \sin \theta \\
0 & -\sin \theta & \cos \theta
\end{array}\right]\left\{\begin{array}{l}
0 \\
\dot{\psi} \\
0
\end{array}\right\} .
$$

Solving (6), the angular velocity vector $\{\omega\}$ is obtained:

$$
\left\{\begin{array}{c}
\omega_{x} \\
\omega_{y} \\
\omega_{z}
\end{array}\right\}=\left\{\begin{array}{ccc}
\dot{\theta} \cos \phi+\dot{\psi} & \sin \phi & \cos \theta \\
-\dot{\theta} \sin \phi+\dot{\psi} & \cos \phi & \cos \theta \\
\dot{\phi}-\dot{\psi} & \sin \theta
\end{array}\right\}
$$

Replacing $\omega_{x}, \omega_{y}$, and $\omega_{z}$ in the kinetic energy $T_{D}$ in Eq. (3) produces

$$
T_{D}=\frac{1}{2} m_{d}\left(\dot{u}^{2}+\dot{v}^{2}\right)+\frac{1}{2} I_{d}\left(\dot{\theta}^{2}+\dot{\psi}^{2} \cos ^{2} \theta\right)+\frac{1}{2} I_{p}(\dot{\phi}-\dot{\psi} \sin \theta)^{2} .
$$

The expression of $T_{D}$ in Eq. (8) is replaced in Eq. (2) to define the EOM on the generalized coordinates.

$$
\begin{gathered}
\frac{d}{d t}\left(\frac{\partial T_{D}}{\partial \dot{u}}\right)-\frac{\partial T_{D}}{\partial u}=m_{d} \ddot{u}=-F_{u} . \\
\frac{d}{d t}\left(\frac{\partial T_{D}}{\partial \dot{v}}\right)-\frac{\partial T_{D}}{\partial v}=m_{d} \ddot{v}=-F_{v} . \\
\frac{d}{d t}\left(\frac{\partial T_{D}}{\partial \dot{\theta}}\right)-\frac{\partial T_{D}}{\partial \theta}=I_{d} \ddot{\theta}+I_{p} \dot{\phi} \dot{\psi} \cos \theta+\left(I_{d}-I_{p}\right) \dot{\psi}^{2} \sin \theta \cos \theta=-F_{\theta} . \\
\frac{d}{d t}\left(\frac{\partial T_{D}}{\partial \dot{\psi}}\right)-\frac{\partial T_{D}}{\partial \psi} \\
=\left(I_{d} \cos ^{2} \theta+I_{p} \sin ^{2} \theta\right) \ddot{\psi}-I_{p} \ddot{\phi} \sin \theta-I_{p} \dot{\phi} \dot{\theta} \cos \theta+2\left(I_{p}-I_{d}\right) \dot{\psi} \dot{\theta} \sin \theta \\
\cos \theta=-F_{\psi} \cdot
\end{gathered}
$$

The expressions (9)-(12) are the nonlinear form of the EOM. Canceling out the higher-order terms and at steady-state conditions, $(\ddot{\phi}=0, \dot{\phi}=\Omega)$, the linear form for small angles can be obtained, as shown in the following equations:

$$
\frac{d}{d t}\left(\frac{\partial T_{D}}{\partial \dot{u}}\right)-\frac{\partial T_{D}}{\partial u}=m_{d} \ddot{u}=-F_{u}
$$




$$
\begin{gathered}
\frac{d}{d t}\left(\frac{\partial T_{D}}{\partial \dot{v}}\right)-\frac{\partial T_{D}}{\partial v}=m_{d} \ddot{v}=-F_{v}, \\
\frac{d}{d t}\left(\frac{\partial T_{D}}{\partial \dot{\theta}}\right)-\frac{\partial T_{D}}{\partial \theta}=I_{d} \ddot{\theta}+I_{p} \Omega \dot{\psi}=-F_{\theta},
\end{gathered}
$$

and

$$
\frac{d}{d t}\left(\frac{\partial T_{D}}{\partial \dot{\psi}}\right)-\frac{\partial T_{D}}{\partial \psi}=I_{d} \ddot{\psi}-I_{p} \Omega \dot{\theta}=-F_{\psi} .
$$

These expressions will be linear if the generalized forces $\left(F_{q_{i}}\right)$ are in linear form as well.

\section{NONLINEAR GENERALIZED FORCES}

The nonlinear generalized forces are calculated using a Newtonian approach. Table 1 defines the displacements and velocities at the end points of Figure 1 (points 1 and 2) on the $x-z$ and $y-z$ planes.

Table 1. Displacement and velocities at the supports.

\begin{tabular}{lcc}
\hline \multicolumn{1}{c}{ Planes } & Plane $\boldsymbol{x}-\boldsymbol{z}$ & Plane $\boldsymbol{y}-\boldsymbol{z}$ \\
\hline Displacement-1 & $u-a \sin \psi$ & $v+a \sin \theta$ \\
Displacement-2 & $u+b \sin \psi$ & $v-b \sin \theta$ \\
Velocity-1 & $\dot{u}-a \dot{\psi} \cos \psi$ & $\dot{v}+a \dot{\theta} \cos \theta$ \\
Velocity-2 & $\dot{u}+b \dot{\psi} \cos \psi$ & $\dot{v}-b \dot{\theta} \cos \theta$ \\
\hline
\end{tabular}

The stiffness $\left(k_{\text {Axis \# }}\right)$ and damping $\left(c_{\text {Axis \# }}\right)$ at the supports at each plane are known where the numbers (\#) denote the end points 1 or 2 . The generalized forces will take the following forms:

$$
\begin{gathered}
F_{u}=k_{x 1}(u-a \sin \psi)+k_{x 2}(u+b \sin \psi)+c_{x 1}(\dot{u}-a \dot{\psi} \cos \psi)+c_{x 2}(\dot{u}+b \dot{\psi} \cos \psi), \\
F_{v}=k_{y 1}(v+a \sin \theta)+k_{y 2}(v-b \sin \theta)+c_{y 1}(\dot{v}+a \dot{\theta} \cos \theta)+c_{y 2}(\dot{v}-b \dot{\theta} \cos \theta) \\
F_{\theta}=a k_{y 1}(v+a \sin \theta)-b k_{y 2}(v-b \sin \theta) \\
+a c_{y 1}(\dot{v}+a \dot{\theta} \cos \theta)-b c_{y 2}(\dot{v}-b \dot{\theta} \cos \theta)
\end{gathered}
$$

and

$$
\begin{gathered}
F_{\psi}=-a k_{x 1}(u-a \sin \psi)-b k_{x 2}(u+b \sin \psi) \\
-a c_{x 1}(\dot{u}-a \dot{\psi} \cos \psi)+b c_{x 2}(\dot{u}+b \dot{\psi} \cos \psi) .
\end{gathered}
$$

The following equations show how the grouping of the common terms is defined:

$$
F_{u}=k_{x T} u+k_{x C} \sin \psi+c_{x T} \dot{u}+c_{x C} \dot{\psi} \cos \psi
$$




$$
\begin{gathered}
F_{v}=k_{y T} v-k_{y C} \sin \theta+c_{y T} \dot{v}-c_{y C} \dot{\theta} \cos \theta, \\
F_{\theta}=-k_{y C} v+k_{y R} \sin \theta-c_{y C} \dot{v}+c_{y R} \dot{\theta} \cos \theta,
\end{gathered}
$$

and

$$
F_{\psi}=k_{x C} u+k_{x R} \sin \psi+c_{x C} \dot{u}+c_{x R} \dot{\psi} \cos \psi
$$

The equivalent stiffness and damping shown in the previous expressions are shown in Appendix A.

\section{LINEAR FORM OF THE EOM}

For steady-state conditions $(\dot{\phi}=\Omega)$, the linearized form of the EOM used to solve the eigenvalues is

$$
[M]\{\ddot{q}\}+(\Omega[G]+[C])\{\dot{q}\}+[K]\{q\}=\{0\} .
$$

The following EOM is used to solve the unbalance response:

$$
[M]\{\ddot{q}\}+(\Omega[G]+[C])\{\dot{q}\}+[K]\{q\}=\{U\},
$$

where the matrices (mass $[M]$, gyroscopic $[G]$, damping $[C]$, and stiffness $[K]$ ), and vector (displacement $\{q\})$ from Eqs. (25) and (26) are defined using Eqs. (13)-(16) and the linearized form of Eqs. (21)-(24):

$$
\begin{gathered}
\{q\}^{T}=\left[\begin{array}{llll}
u & v & \theta & \psi
\end{array}\right], \\
{[M]=\left[\begin{array}{cccc}
m_{d} & 0 & 0 & 0 \\
0 & m_{d} & 0 & 0 \\
0 & 0 & I_{d} & 0 \\
0 & 0 & 0 & I_{d}
\end{array}\right],} \\
{[G]=\left[\begin{array}{cccc}
0 & 0 & 0 & 0 \\
0 & 0 & 0 & 0 \\
0 & 0 & 0 & I_{p} \\
0 & 0 & -I_{p} & 0
\end{array}\right],} \\
{[C]=\left[\begin{array}{cccc}
c_{x T} & 0 & 0 & c_{x C} \\
0 & c_{y T} & -c_{y C} & 0 \\
0 & -c_{y C} & c_{y R} & 0 \\
c_{x C} & 0 & 0 & c_{x R}
\end{array}\right],}
\end{gathered}
$$

and

$$
[K]=\left[\begin{array}{cccc}
k_{x T} & 0 & 0 & k_{x C} \\
0 & k_{y T} & -k_{y C} & 0 \\
0 & -k_{y C}-m_{d} g & k_{y R} & 0 \\
k_{x C}+m_{d} g & 0 & 0 & k_{x R}
\end{array}\right] .
$$

The effect of weight has also been included in the stiffness matrix $[K]$. Finally, the unbalance vector $\{U\}$ [8] is 


$$
\{U\}=\left\{\begin{array}{rr}
m \varepsilon \Omega^{2} & \cos (\Omega t+\delta) \\
m \varepsilon \Omega^{2} & \sin (\Omega t+\delta) \\
-\left(I_{d}-I_{p}\right) \beta \Omega^{2} & \sin (\Omega t+\gamma) \\
\left(I_{d}-I_{p}\right) \beta \Omega^{2} & \cos (\Omega t+\gamma)
\end{array}\right\}
$$

The eccentricity $(\varepsilon)$ of the rotor creates an unbalance $(m \varepsilon)$. If the axis of rotation has an angle $\beta$ relative to its geometric axis, it creates a rotational unbalance of magnitude $\left(I_{d}-I_{p}\right) \beta$. No angular acceleration component exists at steady-state conditions, but this effect will be considered in the solution of the nonlinear cases. The phase angles $\delta$ and $\gamma$ are used to provide correlation between the unbalance and rotational unbalance.

\section{RESULTS FROM THE LINEAR EXAMPLE}

Table 2 contains the rotor data that was used for the examples and came from Friswell et al. [9]. The state-space technique was used for the solution of the eigenvalues [10].

Figure 2 shows the Campbell diagram for the operational range from 0 to $3,800 \mathrm{rpm}$. The intersection points correspond to the vertical rigid-body eigenvalues. The $X$ value denotes the speed $(\Omega)$ at which the eigenvalue was calculated, and the $Y$ value is the actual eigenvalue result.

Table 2. Data from the Dynamics of Rotating Machines [8].

\begin{tabular}{lccc}
\hline \multicolumn{1}{c}{ Input Parameter } & Symbol & Value & Units \\
\hline Moment of inertia (xx and yy) & $I_{d}$ & 2.8625 & $\mathrm{~kg} \mathrm{~m}{ }^{2}$ \\
Polar moment of inertia (zz) & $I_{p}$ & 0.6134 & $\mathrm{~kg} \mathrm{~m}$ \\
Rotor mass & $m_{d}$ & 122.68 & $\mathrm{~kg}$ \\
Acceleration of gravity & $g$ & 9.81 & $\mathrm{~m} / \mathrm{s}^{2}$ \\
Height above CG & $a$ & 0.250 & $\mathrm{~m}$ \\
Height under CG & $b$ & 0.250 & $\mathrm{~m}$ \\
Upper stiffness (H) & $k_{x 1}$ & $1.0 \mathrm{E}+6$ & $\mathrm{~N} / \mathrm{m}$ \\
Lower stiffness (H) & $k_{x 2}$ & $1.3 \mathrm{E}+6$ & $\mathrm{~N} / \mathrm{m}$ \\
Upper stiffness (V) & $k_{y 1}$ & $1.5 \mathrm{E}+6$ & $\mathrm{~N} / \mathrm{m}$ \\
Lower stiffness (V) & $k_{y 2}$ & $1.8 \mathrm{E}+6$ & $\mathrm{~N} / \mathrm{m}$ \\
Upper damping (H) & $c_{x 1}$ & 20.0 & $\mathrm{N.s} / \mathrm{m}$ \\
Lower damping (H) & $c_{x 2}$ & 26.0 & $\mathrm{N.s} / \mathrm{m}$ \\
Upper damping (V) & $c_{y 1}$ & 30.0 & $\mathrm{N.s} / \mathrm{m}$ \\
Lower damping (V) & $c_{y 2}$ & 36.0 & $\mathrm{N.s} / \mathrm{m}$ \\
Rotational unbalance & $\beta$ & 0.0 or $1.0 \mathrm{E}-3$ & $\mathrm{rad}$ \\
Phase angle & $\gamma$ & $\pi / 2$ & $\mathrm{rad}$ \\
Lateral unbalance & $m \varepsilon$ & $1.0 \mathrm{E}-2$ or 0.0 & $\mathrm{~kg} . \mathrm{m}$ \\
Phase angle (in $m \varepsilon$ & $\delta$ & 0.0 & $\mathrm{rad}$ \\
\hline
\end{tabular}




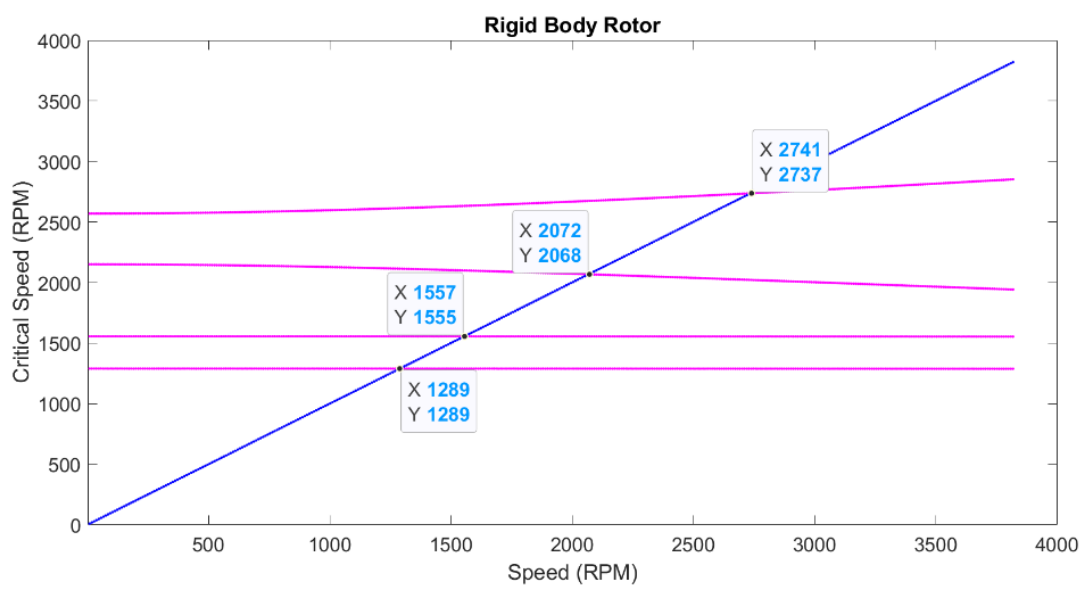

Figure 2. Campbell diagram.

Calculations of the unbalance response were also made at steady-state conditions using the complex form of the EOM [11].

Figures 3 and 4 show the results for the displacements $u$ and $v$ for an unbalance $m \varepsilon=1.0 \mathrm{E}-2 \mathrm{~kg} \cdot \mathrm{m}$ and $\beta=0.0 \mathrm{rad}$.

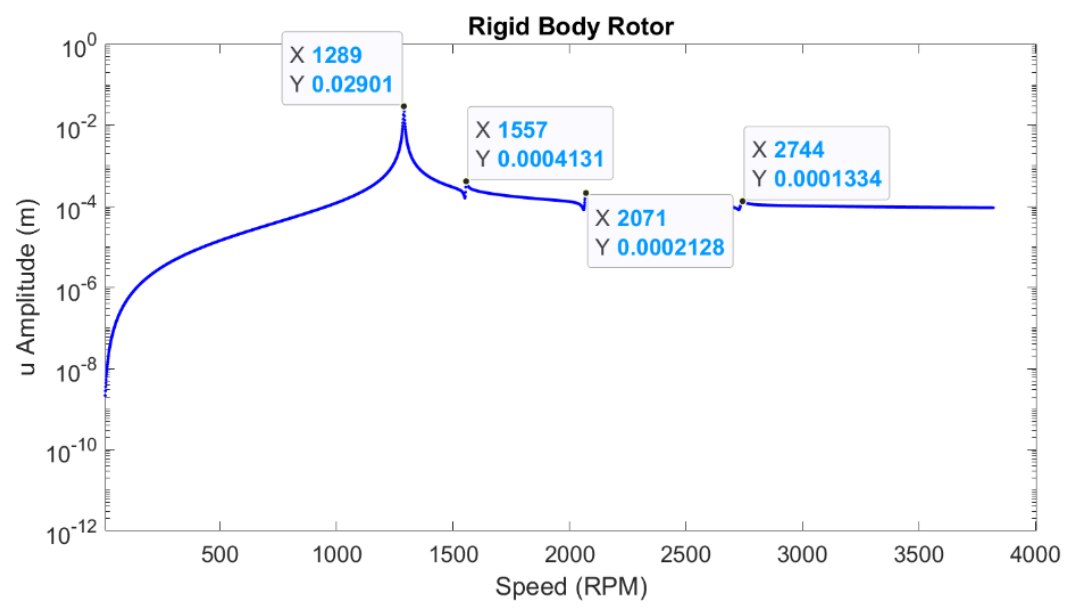

Figure 3. Displacement $u$ amplitude ( $m \varepsilon=1.0 \mathrm{E}-2 \mathrm{~kg} \cdot \mathrm{m}$ and $\beta=0.0 \mathrm{rad})$. 


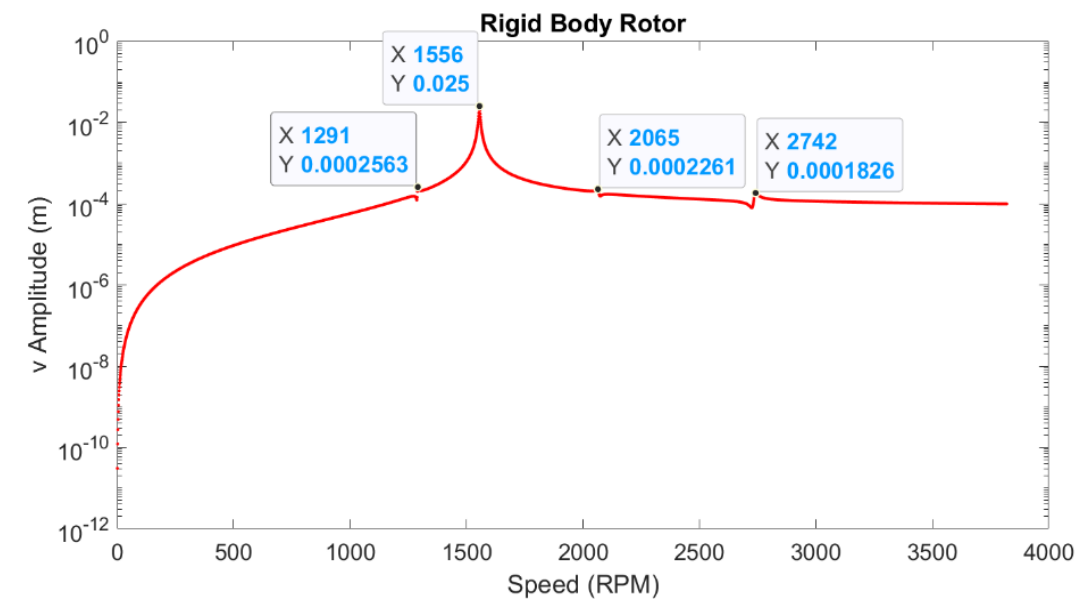

Figure 4. Displacement $v$ amplitude ( $m \varepsilon=1.0 \mathrm{E}-2 \mathrm{~kg} . \mathrm{m}$ and $\beta=0.0 \mathrm{rad})$.

Figures 5 and 6 show the results for the displacements $u$ and $v$ for an unbalance $m \varepsilon=0.0 \mathrm{~kg} . \mathrm{m}$ and $\beta=1.0 \mathrm{E}-3 \mathrm{rad}$.

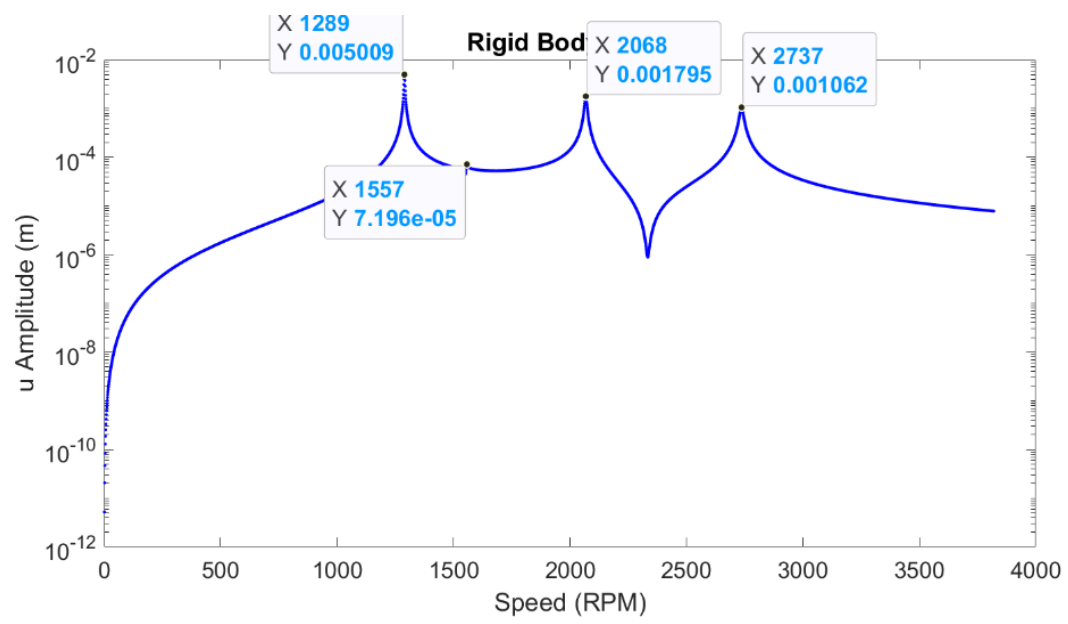

Figure 5. Displacement $u$ amplitude $(m \varepsilon=0.0 \mathrm{~kg} \cdot \mathrm{m}$ and $\beta=1.0 \mathrm{E}-3 \mathrm{rad})$.

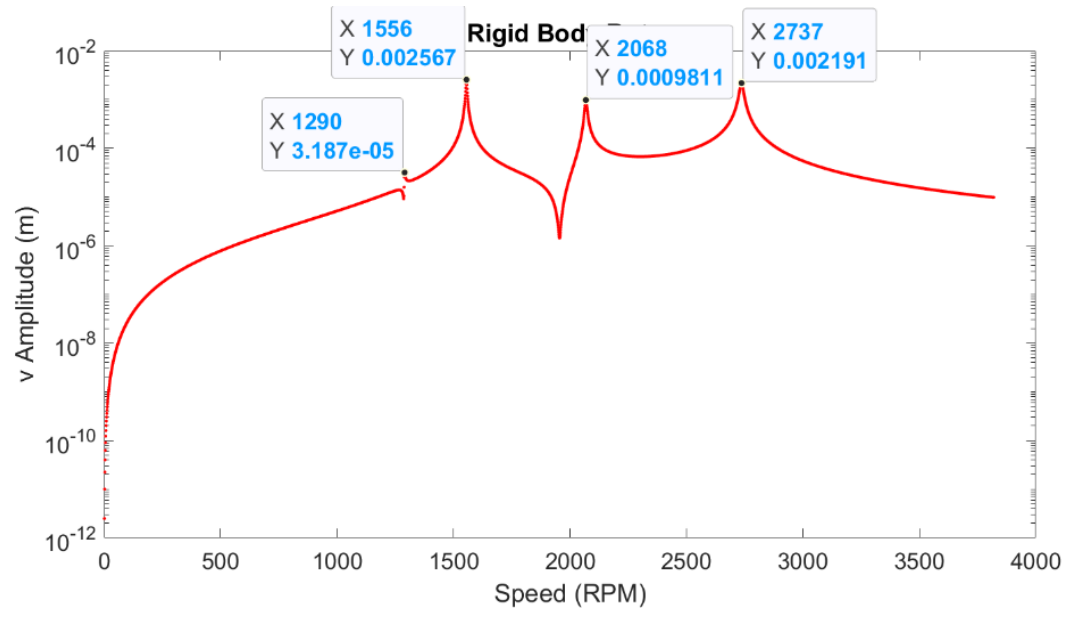

Figure 6. Displacement $v$ amplitude ( $m \varepsilon=0.0 \mathrm{~kg} \cdot \mathrm{m}$ and $\beta=1.0 \mathrm{E}-3 \mathrm{rad})$. 


\section{PROCEDURE FOR SOLVING THE NONLINEAR EOM}

The results from the unbalance response calculations in the linearized EOM were obtained assuming steady-state conditions, but this assumption does not hold for the nonlinear EOM. The process requires a differential equation solver, and for these calculations the MATLAB@ subroutine ode45 was used. Ode45 uses the fourth-order Runge - Kutta method. Also, a time step and the value of the angular acceleration of the driver will be required. For this procedure, it will be assumed that the constant angular acceleration $(\alpha)$, angular velocity, and angular displacement will be defined as a function of $\alpha$ and time $(\mathrm{t})$, as shown in the following equations:

$$
\begin{gathered}
\ddot{\phi}=\alpha=\text { constant }, \\
\dot{\phi}=\alpha t,
\end{gathered}
$$

and

$$
\phi=\frac{1}{2} \alpha t^{2}
$$

The unbalance vector $\{U\}$ will require an extra term (Eq. 32) because of the angular acceleration. The expression for $\{U\}$ is

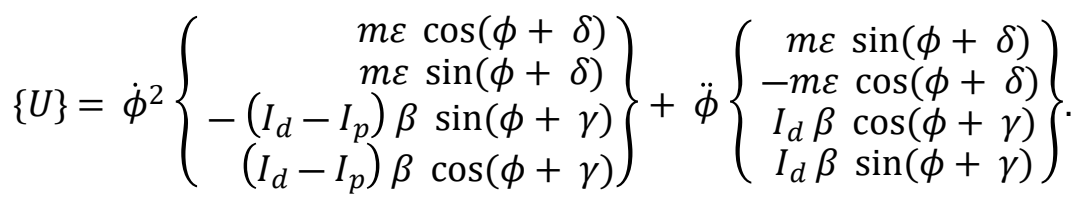

In summary, the EOMs for the nonlinear system are

$$
\begin{gathered}
m_{d} \ddot{u}+F_{u}=U_{1}, \\
m_{d} \ddot{v}+F_{v}=U_{2}, \\
I_{d} \ddot{\theta}+I_{p} \dot{\phi} \dot{\psi} \cos \theta+\left(I_{d}-I_{p}\right) \dot{\psi}^{2} \sin \theta \cos \theta+F_{\theta}=U_{3},
\end{gathered}
$$

and

$$
\begin{gathered}
\left(I_{d} \cos ^{2} \theta+I_{p} \sin ^{2} \theta\right) \ddot{\psi}-I_{p} \ddot{\phi} \sin \theta-I_{p} \dot{\phi} \dot{\theta} \cos \theta \\
+2\left(I_{p}-I_{d}\right) \dot{\psi} \dot{\theta} \sin \theta \cos \theta+F_{\psi}=U_{4} .
\end{gathered}
$$

The values for $\ddot{\phi}, \dot{\phi}, \phi$ are defined by Eqs. (33), (34), and (35). 


\section{RESULTS FOR THE NONLINEAR EXAMPLE}

For the nonlinear example, an angular acceleration of $\alpha=0.01 \mathrm{rad} / \mathrm{s}^{2}$ and a time step of $\delta t=0.001 \mathrm{~s}$ will be used along with the initial conditions for all the parameters. The displacements and their first derivatives are zero.

For comparison purposes, the data for the steady-state calculations will be used for the calculations using the nonlinear EOMs. The results are shown on the following pages (Figures 7-8).

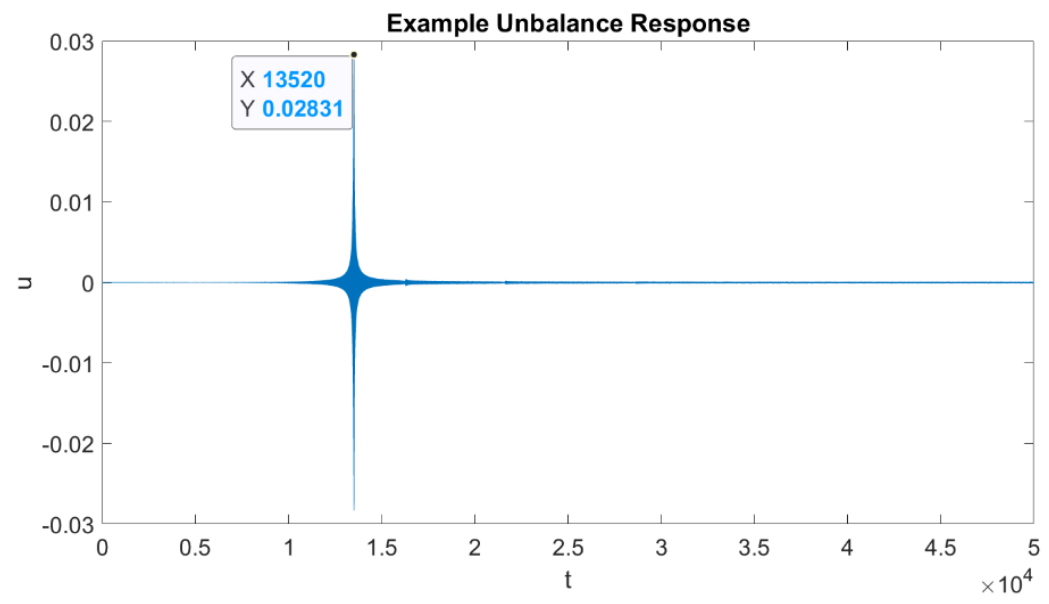

Figure 7. Displacement $u$ amplitude $(m \varepsilon=1.0 \mathrm{E}-2 \mathrm{~kg} . \mathrm{m}$ and $\beta=0.0 \mathrm{rad})$.

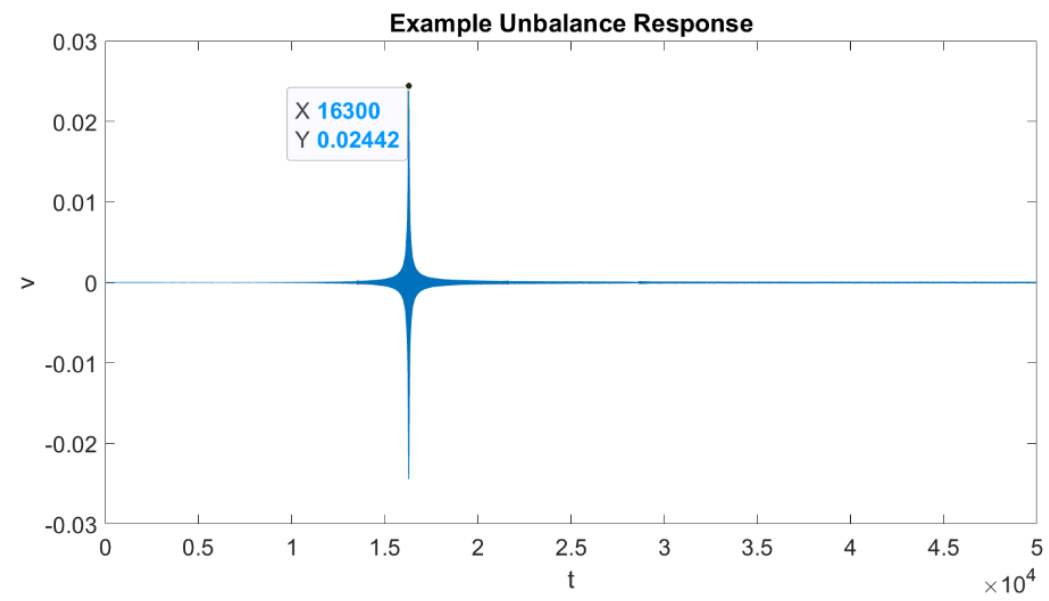

Figure 8. Displacement $v$ amplitude $(m \varepsilon=1.0 \mathrm{E}-2 \mathrm{~kg} . \mathrm{m}$ and $\beta=0.0 \mathrm{rad})$.

The results from the nonlinear calculations compare well with the steady-state values.

As shown in Figure 7, the $u$ amplitude of $0.02831 \mathrm{~m}$ at 1,291 rpm is comparable to the $u$ amplitude of $0.02901 \mathrm{~m}$ at $1,289 \mathrm{rpm}$ in Figure 3.

Similarly, the $v$ amplitude of $0.02442 \mathrm{~m}$ at 1,556 rpm in Figure 8 is comparable to the $v$ amplitude of $0.02500 \mathrm{~m}$ at 1,556 rpm in Figure 4. 
The calculations made at steady-state conditions will always have a larger amplitude than the nonlinear results because in steady-state conditions, infinite time for the amplitude to grow at the critical speed exists. That is not true for the nonlinear case where the angular acceleration $(\alpha)$ must always be greater than zero.

As shown in Figure 9, the $u$ amplitude of $0.004941 \mathrm{~m}$ at $1,290 \mathrm{rpm}$ is comparable to the $u$ amplitude of $0.005009 \mathrm{~m}$ at $1,289 \mathrm{rpm}$ in Figure 5.

Similarly, the $v$ amplitude of $0.02524 \mathrm{~m}$ at $1,556 \mathrm{rpm}$ in Figure 10 is comparable to the $v$ amplitude of $0.02567 \mathrm{~m}$ at 1,556 rpm in Figure 6.

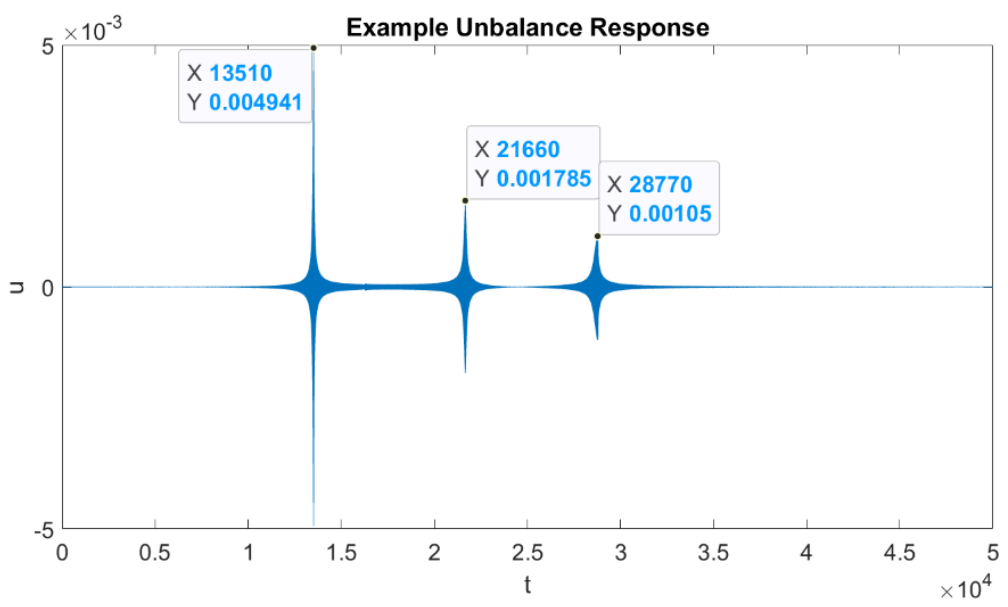

Figure 9. Displacement $u$ amplitude ( $m \varepsilon=0.0 \mathrm{~kg} \cdot \mathrm{m}$ and $\beta=1.0 \mathrm{E}-3 \mathrm{rad})$.

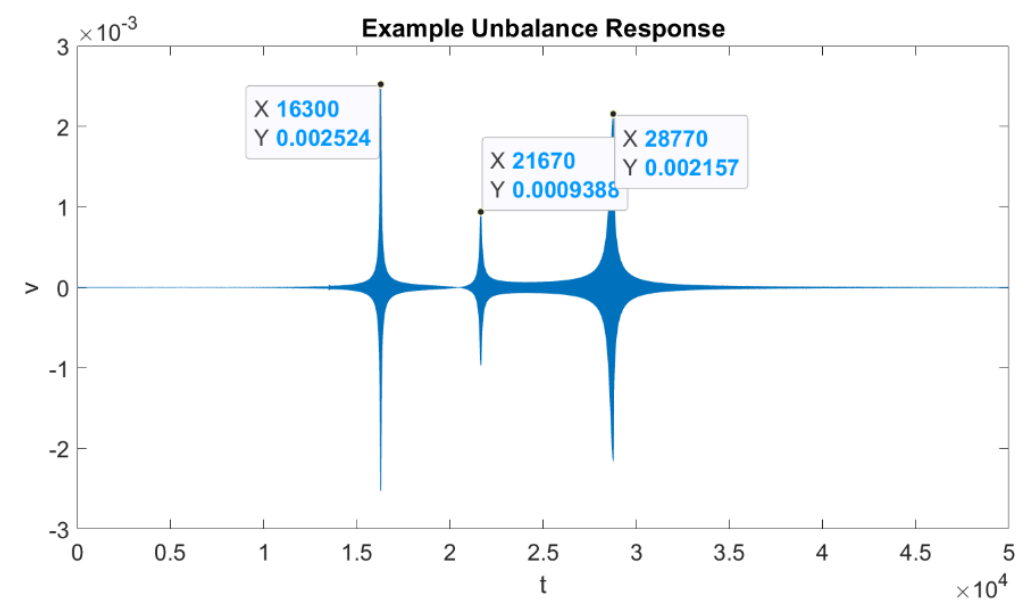

Figure 10. Displacement $v$ amplitude ( $m \varepsilon=0.0 \mathrm{~kg} \cdot \mathrm{m}$ and $\beta=1.0 \mathrm{E}-3 \mathrm{rad})$.

All these results indicate that the unbalance force in the nonlinear cases is producing similar results as in the steady-state conditions for the set of imbalances that were chosen. The next section will show how a change of the $\beta$ angle can bring the system into a chaotic mode. 


\section{EXAMPLE THAT EXHIBITS CHAOTIC BEHAVIOR}

As shown in Eqs. (37)-(40), the EOMs for $\theta$ and $\phi$ are the ones that contain a greater number of higherorder terms, which may lead to sensitivity in nonlinear behavior. The author has corroborated this fact by doing multiple calculations using different values of $m \varepsilon$ and $\beta$ and found that the system response is very sensitive to $\beta$.

The same system parameters will be used for the next calculations, except that the value for $\beta$ will be increased from 1.0E-3 rad to $1.0 \mathrm{E}-2 \mathrm{rad}$ (one order of magnitude increment). The results are shown in Figures 11-12.

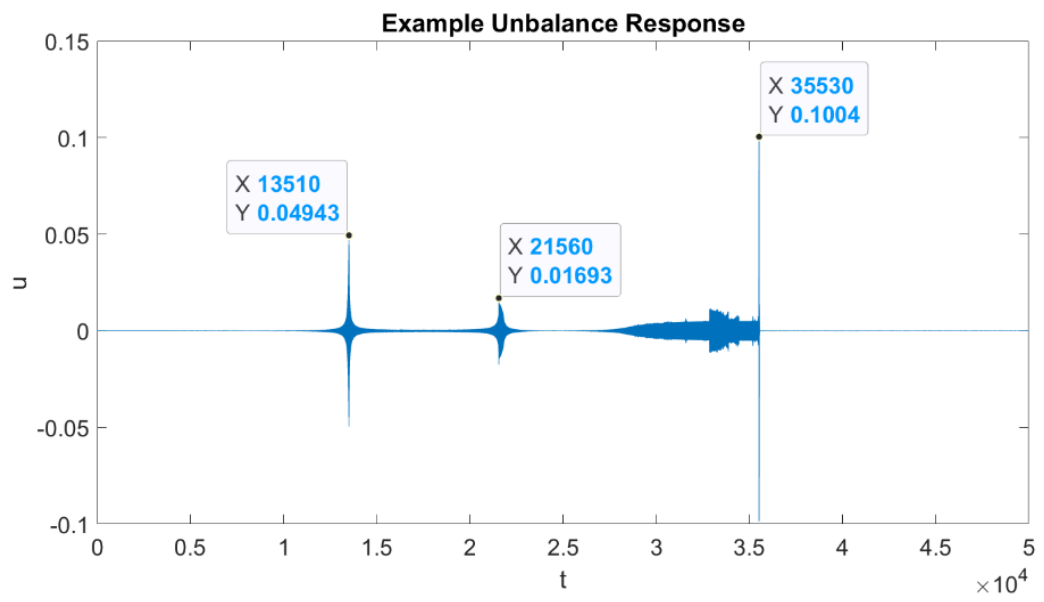

Figure 11. Displacement $u$ amplitude ( $m \varepsilon=0.0$ kg.m and $\beta=1.0 \mathrm{E}-2 \mathrm{rad})$.

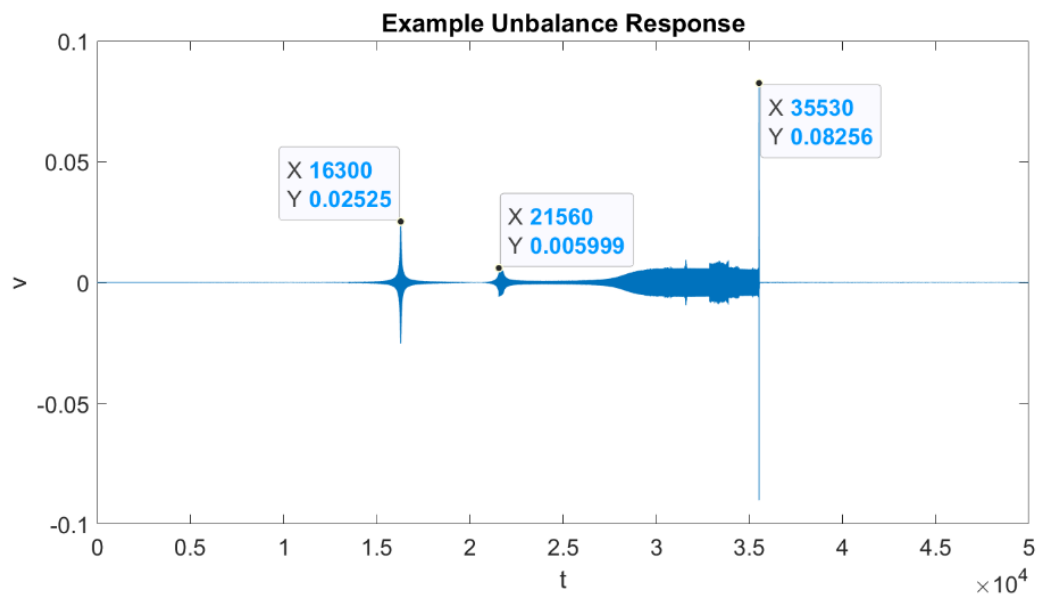

Figure 12. Displacement $v$ amplitude ( $m \varepsilon=0.0 \mathrm{~kg} \cdot \mathrm{m}$ and $\beta=1.0 \mathrm{E}-2 \mathrm{rad})$.

Notably, in Figures 11 and 12, the first two critical speeds (1,289 and 1,556 rpm, which are associated with $u, v$, respectively) remain linear. The amplitude at $1,289 \mathrm{rpm}$ in Figure 11 is one order of magnitude larger than the value in Figure 9. The amplitude at 1,556 rpm in Figure 12 is one order of magnitude larger than the value in Figure 10. However, once the speed reached the last two critical speeds (which are related to $\theta, \psi)$, the response was nonlinear. 
For the next critical speed, the maximum amplitude is located at 2,059 rpm, which is slightly lower than the linear eigenvalue of 2,068 rpm. Also, the curves (at $u$ and $v$ ) no longer behave in a strictly vertical form, which is the so-called "softening spring" nonlinear behavior.

The next linear critical speed is predicted at $2,737 \mathrm{rpm}$; starting at about that speed, a change in the behavior in the system can be observed. At 3,393 rpm, a "jump" of very short duration but of high intensity occurs. This behavior is depicted in full in the orbits shown in Figures 13 and 14.

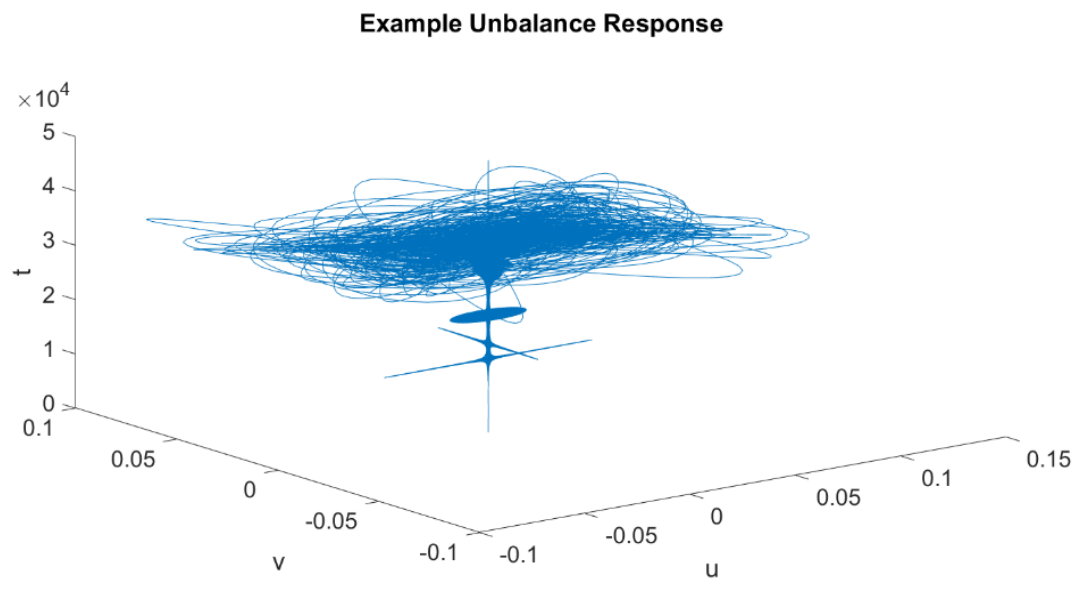

Figure 13. Orbits on the $x-y$ plane shown in time (vertical axis).

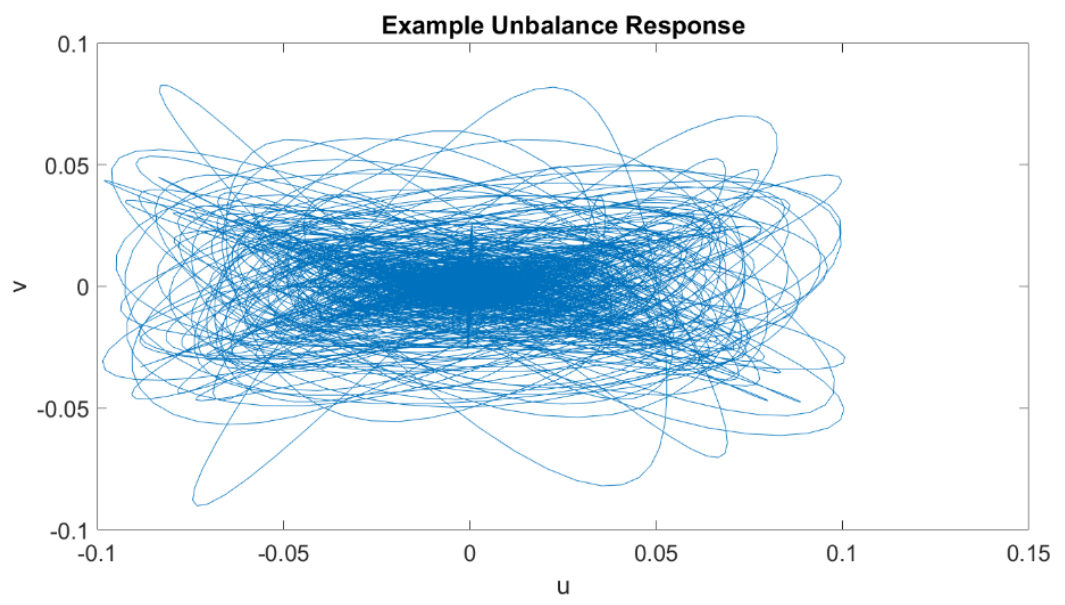

Figure 14. Orbits on the $x-y$ plane for the entire operational range.

After the jump, the system reaches steady-state conditions and remains there for the duration of the calculations. Definitions like "softening spring," "hardening spring," and "jump" are common in nonlinear theory, and a short explanation of the Duffing equation in the next section will provide a better understanding of these topics.

\section{DUFFING EQUATION}

The Duffing equation [12] will be used to explain some of the nonlinear features that were observed in the vertical rigid-rotor example. The Duffing equation is 


$$
\ddot{x}+c \dot{x}+\omega_{n}^{2} x \pm \mu x^{3}=F \cos (\omega t+\phi) .
$$

The nonlinear stiffness $\mu x^{3}$ can have a positive or negative sign and will define the system as a hardening or softening spring.

The frequency response is calculated from the following expression:

$$
F^{2}=\left[\left(\omega_{n}^{2}-\omega^{2}\right) A+\frac{3}{4} \mu A^{3}\right]+[c \omega A]^{2}
$$

where $A$ is the amplitude of the solution for $x$.

$$
x=A \cos (\omega t)
$$

Figure 15 shows the frequency response as a function of the excitation frequency $(\omega)$ with $c=0.1, \omega_{n}^{2}$ $=1.0, F=1.0$, and values of $\mu=-0.003 \rightarrow 0.040$. Brennan et al. [13] show results in a similar fashion as Figure 15.

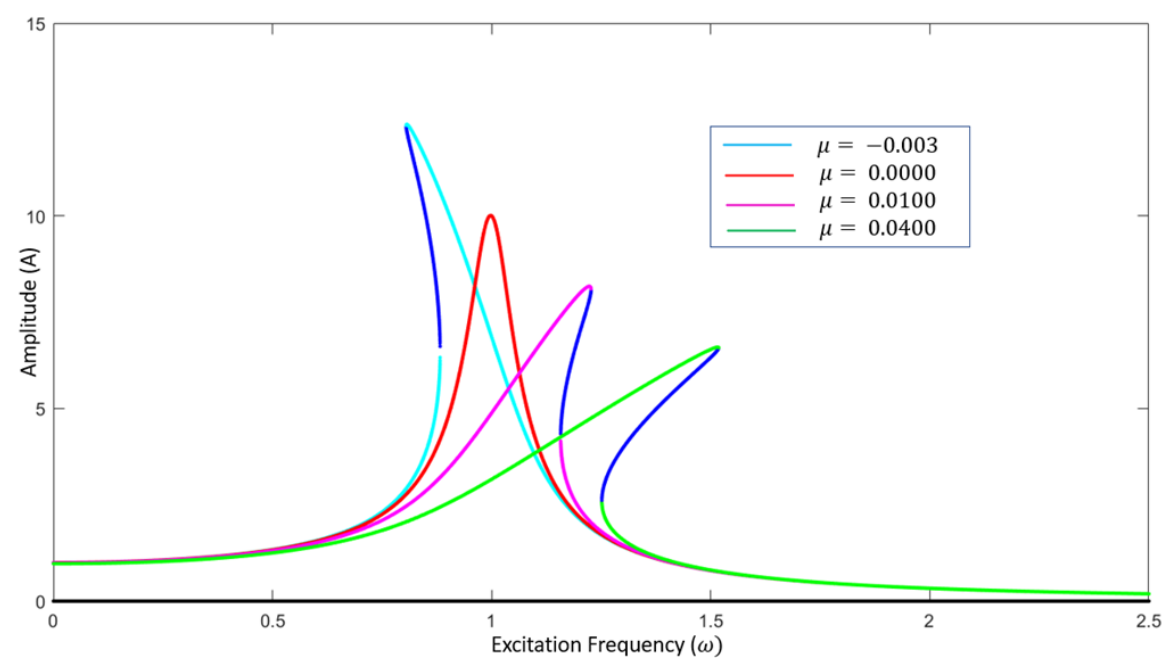

Figure 15. Frequency response.

The red line represents the frequency response in the absence of any nonlinearity. The magenta and green lines correspond to hardening-spring cases for different degrees of $\mu$. The cyan line is a case for the softening-spring example. The blue lines are "exclusion zones," which means no vibrational activity will occur in this unstable area, and the curve will have to follow a different path on the run-up or coast-down. Figure 16 shows the paths used to avoid the unstable zone. 


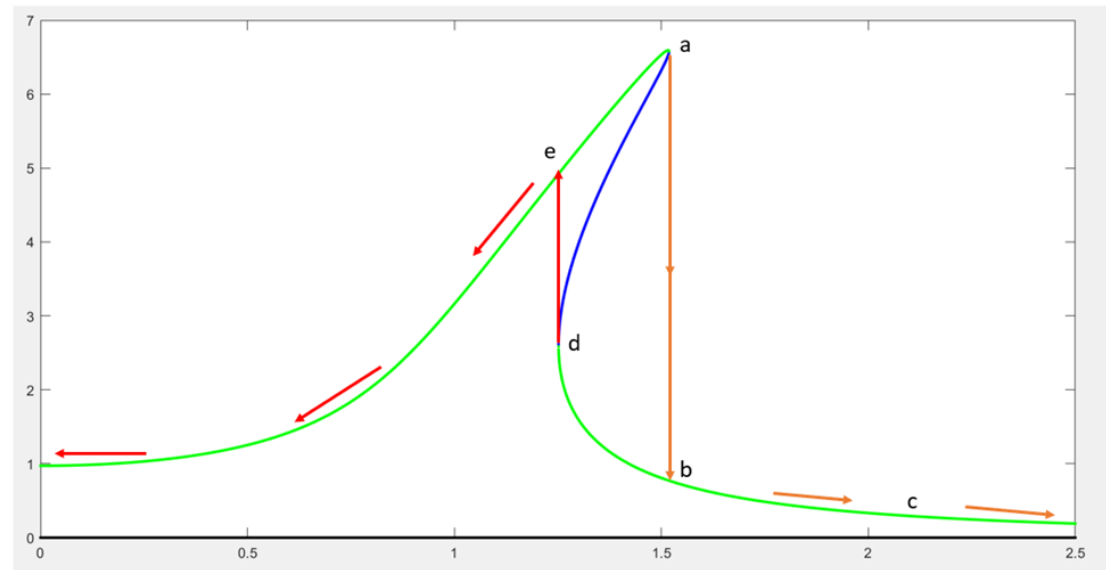

Figure 16. Frequency response $(\mu=0.0400)$; jump phenomena-paths to follow.

On the run-up from the peak amplitude at point a, no other possibility exists but to go to $b$ and then continue all the way up in speed to c. On the coast-down, point c will move to d, and the only way to be able to continue the descent in frequency is to move up to point $\mathrm{e}$.

The same parameters used to determine the frequency response will be used to calculate the transient for $\mu=0.0400$. This is shown in Figure 17 .

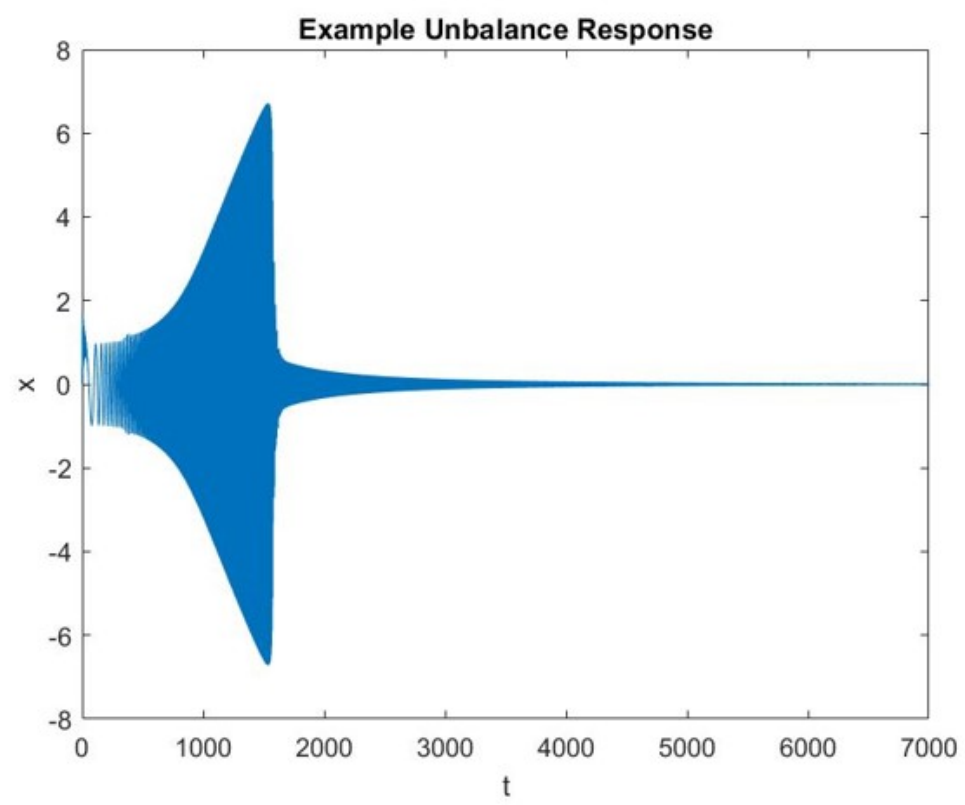

Figure 17. Transient result for $\boldsymbol{\mu}=\mathbf{0 . 0 4 0 0}$.

The peak amplitude of Figure 17 is very similar to the peak value of Figure 16 that was calculated for steady-state conditions with the same parameters. Figure 17 clearly depicts the jump from the peak value in the manner predicted for a hardening-spring, nonlinear system $(\mu=0.04)$. 
With a change of parameters, inducing a chaotic response is possible, as shown in Figure 18.

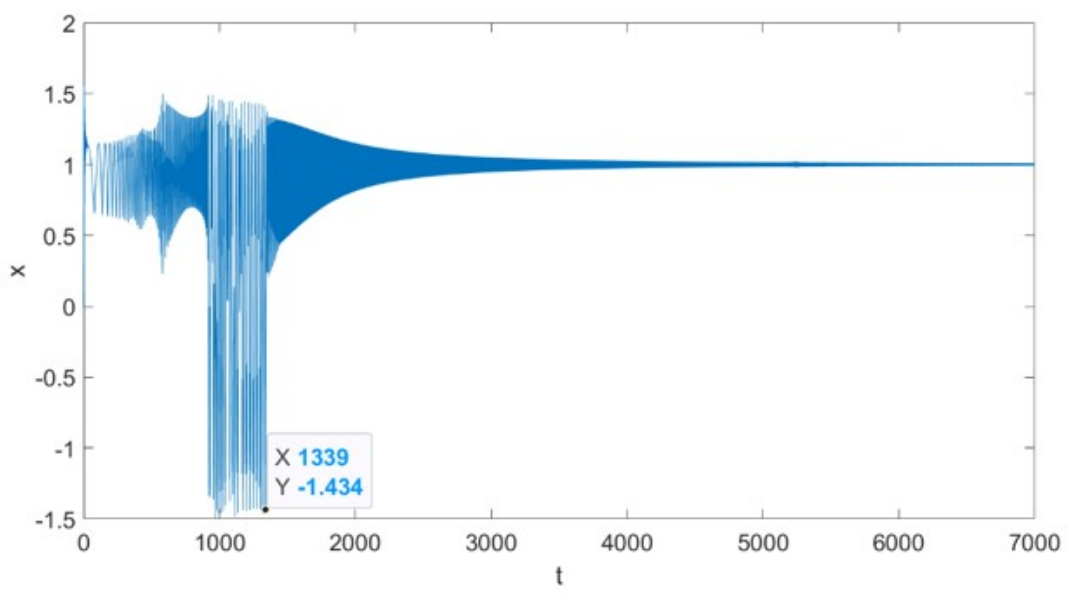

Figure 18. Chaotic response.

The set of adimensional parameters used in Figure 18 were $c=0.3, \omega_{n}^{2}=-1.0, F=0.37$, and $\mu=1.0$ . The negative sign in the $\omega_{n}^{2}$ term only means that the linear stiffness is negative.

These examples clearly illustrate the response of a nonlinear system and help put the results shown in Figures 11-14 into perspective.

\section{SOURCES OF NONLINEARITIES ON ROTORS}

Nonlinearities in rotors are a very common phenomena and are the source of instabilities in a rotorbearing system. By nature, most of the systems are nonlinear but have operational conditions that tend to avoid the nonlinear range. Among these conditions are large imbalances (the topic of this paper), fluidfilm-bearing parameters, labyrinth seals clearances, internal stiffness, internal damping, and so on. The most important sources of nonlinearities on rotors are described in the following paragraphs.

Residual unbalance. As shown in this paper, an excess of residual unbalance (of the rotational type) could introduce softening- and hardening-spring effects on the system, and for very large values (of unbalance) it can lead to chaotic conditions on the system. During the preparation of this paper the author was also able to excite the lateral modes if the residual lateral unbalance is large enough.

Fluid-film bearings. These bearings can show nonlinear behavior at large speeds, which is when the journal whirls close to the bearing geometrical center. The rotor dynamic program Dyrobes can simulate the effect of the journal bearings in the unbalance response of the rotor-bearing system.

Internal stiffness. Most of the rotors have materials that are isotropic, which means that the material has the same properties in all directions, but orthotropic materials exist that will have different properties in orthogonal directions, which are the sources of instabilities in the rotor-bearing system. However, if a rotor is required to be designed with asymmetric cross sections, as with the case of a two-pole generator rotor for power generation, then this rotor at the balancing stand will encounter instabilities due to thermal expansion as a result of the rotor asymmetry with large electrical currents that generate heat. Ways to counteract this phenomena exist, and several rotordynamic books [2] will have a detailed explanation of this phenomena. 
Labyrinth seals. These devices are used to control the interstage leaking in rotating machinery but are also the source of instabilities. The fluid inside the labyrinth seal will introduce forces on the system with strong values of cross-coupled stiffness $\left(\mathrm{K}_{\mathrm{xy}}, \mathrm{K}_{\mathrm{yx}}\right)$ that, when combined, will produce a tangential force on the system in opposition to the external damping from the rotor-bearing system. If the cross-couple stiffnesses are large enough, the net damping will be zero or negative, in which case the rotor turns unstable with a subsynchronous trace. Laboratory tests have shown that the tangential forces generated on a labyrinth seal are a strong function of the "swirl" of the fluid. Anti-swirl devices are used to counteract this phenomenon, and special seal designs like the honeycomb seal are designed to reduce the swirl content.

In summary, all the mentioned examples have the same source - the cross-couple terms, $\mathrm{K}_{\mathrm{xy}}, \mathrm{K}_{\mathrm{yx}}$, which are generated by different mechanisms on the rotor-bearing system.

\section{CONCLUSIONS}

- The results from the nonlinear calculations compare well with the steady-state values if the unbalances are in the low- to moderate-value range.

- The practice of accelerating the rotor during the run-up reduces the amplitudes of motion in the rotorbearing system, which facilitates crossing through the critical speeds. The same angular acceleration value (but with the opposite sign) should be used during the coast-down to minimize the amplitudes of motion as well.

- Large unbalances will trigger a nonlinear response, and the $\theta, \psi$ terms are the most sensitive to this effect, which explains the need to have good control of the rotational unbalance in the rotor-bearing system.

- Notably, in Figures 11 and 12, the first two critical speeds (1,289 and 1,556 rpm, which are associated with $u$ and $v$, respectively) remain linear.

- The nonlinear motions are triggered with large values of $\beta$, and the nonlinear effects showed up in the form of softening-spring and chaotic motions for the last two critical speeds, respectively. 


\section{REFERENCES}

[1] Laos, H., 2021. Oak Ridge National Laboratory, "Equations of Motion for the Vertical Rigid-Body Rotor: Linear and Nonlinear Cases.” Special Topics in Structural Dynamics \& Experimental Techniques, Volume 5, Proceedings of the $39^{\text {th }}$ IMAC, A Conference and Exposition on Structural Dynamics 2021, 39-54.

[2] Lalanne, M. and Ferraris, G. 1999. Rotordynamics Prediction in Engineering, second edition. New York: Wiley, 1.

[3] Friswell, M. I., Penny, J. E. T., Garvey, S. D., and Lees, A. W. 2010. Dynamics of Rotating Machines. New York: Cambridge University Press, 158.

[4] Lalanne and Ferraris, 2.

[5] Friswell et al., 157.

[6] Lalanne and Ferraris, 2.

[7] Vance, J. 1988. Rotordynamics of Turbomachinery. New York: Wiley, 121.

[8] Friswell et al., 246.

[9] Friswell et al., 247.

[10] Friswell et al., 39.

[11] Friswell et al., 246.

[12] Thompson, W. T. and Dahleh, M. D. 1998. Theory of Vibration with Applications, fifth edition. Pearson/Prentice Hall, 448.

[13] Brennan, M. J., Kovacic, I., Carella, A., and Waters, T. P. 2008. "On the Jump-Up and Jump-Down Frequencies of the Duffing Oscillator," Journal of Sound and Vibration 318: 1250-1261. 


\section{APPENDIX A.}

$k_{x T}=k_{x 1}+k_{x 2}$

$k_{x C}=-a k_{x 1}+b k_{x 2}$

$k_{x R}=a^{2} k_{x 1}+b^{2} k_{x 2}$

$k_{y T}=k_{y 1}+k_{y 2}$

$k_{y C}=-a k_{y 1}+b k_{y 2}$

$k_{y R}=a^{2} k_{y 1}+b^{2} k_{y 2}$

$c_{x T}=c_{x 1}+c_{x 2}$

$c_{x C}=-a c_{x 1}+b c_{x 2}$

$c_{x R}=a^{2} c_{x 1}+b^{2} c_{x 2}$

$c_{y T}=c_{y 1}+c_{y 2}$

$c_{y C}=-a c_{y 1}+b c_{y 2}$

$c_{y R}=a^{2} c_{y 1}+b^{2} c_{y 2}$ 
